\title{
New Analytical Monographs on TCM Herbal Drugs for Quality Proof
}

\author{
Hildebert Wagner $^{\mathrm{a}}$ Rudolf Bauer ${ }^{\mathrm{b}}$ Dieter Melchart ${ }^{\mathrm{c}, \mathrm{d}}$ \\ ${ }^{a}$ Center of Pharma Research, Department Pharmacy, Ludwig-Maximilians-Universität München, Munich, Germany \\ ${ }^{\mathrm{b}}$ Institute of Pharmaceutical Sciences, Karl-Franzens-Universität Graz, Graz, Austria \\ ${ }^{c}$ Competence Centre for Complementary Medicine and Naturopathy, Klinikum rechts der Isar, Technische Universität München, Munich, \\ Germany \\ d Institute for Complementary and Integrative Medicine, University Hospital Zurich and University of Zurich, Zurich, Switzerland
}

\section{Keywords}

TCM herbal drug · Monograph · Quality proof · Analytical methods

\section{Summary}

Regardless of specific national drug regulations there is an international consensus that all TCM drugs must meet stipulated high quality standards focusing on authentication, identification and chemical composition. In addition, safety of all TCM drugs prescribed by physicians has to be guaranteed. During the 25 years history of the TCM hospital Bad Kötzting, 171 TCM drugs underwent an analytical quality proof including thin layer as well as high pressure liquid chromatography. As from now mass spectroscopy will also be available as analytical tool. The findings are compiled and already published in three volumes of analytical monographs. One more volume will be published shortly, and a fifth volume is in preparation. The main issues of the analytical procedure in TCM drugs like authenticity, botanical nomenclature, variability of plant species and parts as well as processing are pointed out and possible ways to overcome them are sketched.

(c) 2016 S. Karger GmbH, Freiburg

\section{Legislation}

When we started this work 25 years ago, we noticed that the methods stipulated in the former Chinese Pharmacopoeias were not sufficient to meet the high standards of the official German and

\section{Schlüsselwörter}

TCM-Arzneimittel · Monografie · Qualitätskontrolle · Analytische Methodik

\section{Zusammenfassung}

Ungeachtet spezifischer nationaler Arzneimittelregulierungen gibt es einen internationalen Konsens darüber, dass sämtliche TCM-Präparate verbindlichen qualitative hochstehenden Standards entsprechen müssen, die an der Echtheitsprüfung, Identifizierung und chemischen Komposition orientiert sind. Zudem muss die Sicherheit der von Ärzten verschriebenen TCM-Arzneien gewährleistet sein. In der nunmehr 25-jährigen Geschichte der TCM-Klinik Bad Kötzting wurden 171 TCM-Präparate einer analytischen Qualitätsprüfung unterzogen, unter anderem mittels einer Dünnschichtchromatografie sowie einer Hochdruckflüssigkeitschromatografie. Zudem wird jüngst die Spektroskopie als analytisches Instrument eingesetzt. Die Ergebnisse dieser Testverfahren sind bereits zusammengefasst und in drei entsprechenden Bänden publiziert; weitere Publikationen sind derzeit in Vorbereitung. Hier werden die wichtigsten Herausforderungen der Analyse wie Echtheitsprüfung, botanische Nomenklatur, Variabilität der Pflanzenspezies und -teile sowie Aufbereitung hervorgehoben und potenzielle Lösungsmöglichkeiten skizziert.

European drug regulatory authorities. Among the various prerequisites for a perfect quality proof of these herbal drugs, authentication and safety proof took precedence. Identification was at first primarily synonymous with the macroscopic and microscopic botanical authenticity. Since that time, however, chemical composi-

\section{KARGER \\ Fax +497614520714

\section{(c) 2016 S. Karger GmbH, Freiburg}

$1661-4119 / 16 / 0237-0016 \$ 39.50 / 0$ 
tion and particularly the complex entities of the low molecular constituents have become of greater interest for oral medicinal application and thus in evaluating the pharmacological effects and therapeutic efficacy of the plant drug extracts obtained by decoction or other extraction processes.

Independent of the specific national drug regulations for countries around the world, there is also an international consensus that all TCM drugs must meet certain stipulated high quality standards. Additionally, it must be guaranteed that all TCM drugs prescribed by physicians are safe for patients. The safety proof aims mainly to exclude any kind of possible falsifications of the herbal drugs and to ensure a limited concentration of heavy metals, aflatoxins and defined microbial adulterations.

\section{Applied Methods in Quality Proof}

The main method used is the TLC (thin layer chromatography), which allows us to visualise the main characteristic constituents as coloured TLC photographs. The second, globally used method is HPLC (high-pressure liquid chromatography) in the form of a socalled fingerprint analysis. This technique allows us to detect the complex entities of all low-molecular constituents of a plant drug extract, with the advantage that the single constituents can be made visible in the form of peak profiles. Additionally, the single constituents can be quantified by using online-recordable UV spectra with the diode array. It is also possible to gain preliminary information as to which chemical structure type the single compounds may belong. From that year on, LC-MS (liquid chromatographymass spectrometry) is also available for the analysis of plant extracts whose chemical compositions have previously been investigated only minimally.

\section{Analytical Monographs of Investigated Herbal Chinese Drugs}

The following volumes were / are going to be published by Springer, with financial support from the TCM hospital Bad Kötzting [1-3]:

- Vol. I and II (2011) containing 80 analytical monographs

- Vol. III (2015) containing 23 analytical monographs

- Vol. IV (2016) containing 22 analytical monographs (publication scheduled for July 2016)

- Volume V is currently in preparation; the publication is scheduled for February/March 2017.

A list of all completed analytical monographs of TCM drugs is presented in table 1 and table 2. (All single analytical monographs published can be purchased at www.springer.com/de/book/ 9783709107621). One example for an investigated herbal Chinese drug is Artemisia annua L. which recently gained attention in reference to the Nobel Prize in Medicine in 2015 awarded to the Chinese Professor Dr. Tu Youyou, Beijing (fig. 1) who isolated artemisinin as the main constituent of this plant. Today, artemisinin is

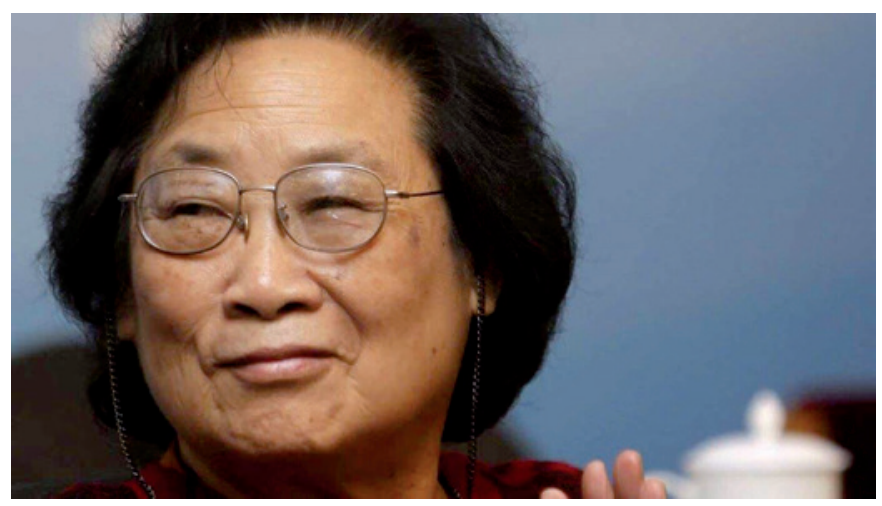

Fig. 1. Tu Youyou.

applied in combination with various chemosynthetic drugs (e.g., mefloquin) in the treatment of malaria.

\section{Prospects for Improvement of Quality Proof of Chinese Herbal Drugs}

\section{Authenticity of TCM Drugs Not Definitely Assessed}

Some herbal drugs originated from wild collections are not yet cultivated under controlled conditions. If they are derived from cultivations it must be taken into account that they may originate from quite different climate zones and are harvested under different conditions. Therefore, their chemical authenticity and homogeneity within a defined plant species often cannot be guaranteed. We have thus investigated as many herbal drug samples as we were able to acquire from different districts, climate zones and markets in China, as well as reference drugs from some German herbal drug firms that also import herbal drugs from China.

\section{Lacking Information on Plant Parts}

In $5-10 \%$ of imported plant drugs from China, we do not receive any specific information about the plant part (flos, fructus, semen, folium, cortex or radix and rhizoma) from which they were derived. Such drugs are specified as 'herba' analogues in the Chinese Pharmacopoeia. For these drug samples, it cannot be expected that the TLC and HPLC chemical fingerprints are homogenous. Not all parts of a herbal drug contain the same chemical constituents. The documentation in the corresponding herbal analytical monographs confirms this assessment (e.g. Herba Leonuri, vol. II; Herba Lysimachiae, vol. III or Herba Violae, vol. IV). Therefore, it will be necessary to correct this discrepancy in one of the following Chinese Pharmacopoeia publications. Otherwise, it is unlikely to reproduce the results of clinical application.

\section{Uncertain Botanical Nomenclature}

The non-uniform nomenclature for the same plant from various regions of China can cause impermissible confusions or falsifications. This occurred some years ago when the root of Stephania 
Table 1. Contents, alphabetically (Latin nomenclature)

\begin{tabular}{|c|c|}
\hline Monograph & Volume \\
\hline Acanthopanacis senticosi, Radix & I \\
\hline Achyranthis, Radix & III \\
\hline Aconiti kusnezofii, Radix & II \\
\hline Aconiti lateralis, Radix & II \\
\hline Acori calami, Rhizoma & II \\
\hline Acori tatarinowii, Rhizoma & II \\
\hline Albiziae, Cortex & IV \\
\hline Alismatis, Rhizoma & II \\
\hline Allii Tuberosi, Semen & $\mathrm{V}^{*}$ \\
\hline Alpiniae Katsumadai, Semen & $\mathrm{V}^{*}$ \\
\hline Amomi rotundus, Fructus & I \\
\hline Ampelopsis, Radix & $\mathrm{V}^{*}$ \\
\hline Andrographis, Herba & I \\
\hline Anemarrhenae, Rhizoma & I \\
\hline Angelicae dahuricae, Radix & I \\
\hline Angelicae pubescentis, Radix & I \\
\hline Angelicae sinensis, Radix & I \\
\hline Apocyni veneti, Folium & III \\
\hline Arctii, Fructus & IV \\
\hline Arecae, Pericarpium & $\mathrm{V}^{*}$ \\
\hline Armeniacae, Semen & $\mathrm{V}^{*}$ \\
\hline Arnebiae, Radix & $\mathrm{V}^{*}$ \\
\hline Artemisiae annuae, Herba & IV \\
\hline Artemisiae argyi, Folium & IV \\
\hline Artemisiae scoparia, Herba & II \\
\hline Asari, Herba & I \\
\hline Astragali, Radix & I \\
\hline Atractylodes macrocephalae, Rhizoma & I \\
\hline Atractylodis lanceae, Radix & II \\
\hline Aucklandiae, Radix & III \\
\hline Aurantii immaturus, Fructus & $\mathrm{V}^{*}$ \\
\hline Aurantii, Fructus & $\mathrm{V}^{*}$ \\
\hline Bambusae, Caulis & III \\
\hline Belamcandae sinensis, Rhizoma & I \\
\hline Bupleuri, Radix & I \\
\hline Camelliae, Folium & II \\
\hline Carthami, Flos & II \\
\hline Cassiae, Semen & II \\
\hline Celosiae, Semen & IV \\
\hline Chaenomelis, Fructus & II \\
\hline Chrysanthemi, Flos & $\mathrm{V}^{*}$ \\
\hline Cimicifugae, Rhizoma & II \\
\hline Cinnamomi, Cortex & II \\
\hline Citri reticulatae viride, Pericarpium & II \\
\hline Citri reticulatae, Pericarpium & II \\
\hline Clematidis, Radix & I \\
\hline Cnidii, Fructus & II \\
\hline Codonopsis pilosulae, Rhizoma & I \\
\hline Coptidis, Rhizoma & I \\
\hline Corni, Fructus & IV \\
\hline Corydalis, Rhizoma & II \\
\hline Crataegi, Fructus et Folium & III \\
\hline Curcumae longae, Radix & II \\
\hline Curcumae, Radix & II \\
\hline Curcumae, Rhizoma & II \\
\hline Cuscutae, Semen & $\mathrm{V}^{*}$ \\
\hline
\end{tabular}

\begin{tabular}{|c|c|}
\hline Monograph & Volume \\
\hline Cyperi, Rhizoma & III \\
\hline Desmodii styracifolii, Herba & III \\
\hline Dictamni, Cortex & $\mathrm{V}^{*}$ \\
\hline Dioscoreae hypoglaucae, Rhizoma & II \\
\hline Dioscoreae nipponicae, Rhizoma & II \\
\hline Dioscoreae oppositae, Rhizoma & II \\
\hline Dioscoreae septemlobae, Rhizoma & II \\
\hline Dipsaci, Radix & II \\
\hline Drynariae, Rhizoma & I \\
\hline Ecliptae, Herba & I \\
\hline Ephedrae, Herba & IV \\
\hline Epimedii, Herba & II \\
\hline Equiseti hiemalis, Herba & $\mathrm{V}^{*}$ \\
\hline Eriocauli, Flos & III \\
\hline Eucommiae, Cortex & II \\
\hline Evodiae, Fructus & I \\
\hline Forsythiae, Fructus & I \\
\hline Fraxini, Cortex & IV \\
\hline Frittilariae, Bulbus & I \\
\hline Ganoderma & II \\
\hline Gardeniae, Fructus & I \\
\hline Gastrodiae, Rhizoma & I \\
\hline Gentianae macrophyllae, Radix & IV \\
\hline Ginkgo, Folium & $\mathrm{V}^{*}$ \\
\hline Ginseng, Radix et Rhizoma & II \\
\hline Glehniae, Radix & $\mathrm{V}^{*}$ \\
\hline Glycyrrhizae, Radix et Rhizoma & III \\
\hline Gynostemmatis, Herba & III \\
\hline Houttuyniae cordatae, Herba & I \\
\hline Isatidis, Radix & II \\
\hline Kochiae, Fructus & IV \\
\hline Leonuri, Herba & II \\
\hline Ligustici chuanxiong, Radix & I \\
\hline Ligustri lucidi, Fructus & III \\
\hline Linderae, Radix & $\mathrm{V}^{*}$ \\
\hline Lonicerae japonicae, Caulis & II \\
\hline Lonicerae japonicae, Flos & II \\
\hline Lonicerae, Flos & II \\
\hline Luffae, Fructus & III \\
\hline Lycii radicis, Cortex & II \\
\hline Lycii, Fructus & II \\
\hline Lycopi lucidi, Herba & I \\
\hline Lycopodii, Herba & III \\
\hline Lysimachiae christinae, Herba & III \\
\hline Magnoliae officinalis, Cortex & I \\
\hline Magnoliae, Flos & II \\
\hline Mori radicis, Cortex & II \\
\hline Mori, Folium & II \\
\hline Mori, Ramulus & IV \\
\hline Morindae officinalis, Radix & III \\
\hline Moutan, Cortex & III \\
\hline Myrrha & $\mathrm{V}^{*}$ \\
\hline Notoginseng, Radix et Rhizoma & II \\
\hline Notopterygii, Rhizoma seu Radix & I \\
\hline Oldenlandiae, Herba & III \\
\hline Olibanum & $\mathrm{V}^{*}$ \\
\hline Ophiopogonis, Radix & II \\
\hline Paeoniae albae/rubrae, Radix & I \\
\hline
\end{tabular}

\begin{tabular}{|c|c|}
\hline Monograph & Volume \\
\hline Persicae, Semen & $\mathrm{V}^{*}$ \\
\hline Peucedani, Radix & III \\
\hline Phellodendri amurensis, Cortex & II \\
\hline Phellodendri chinensis, Cortex & II \\
\hline Picrorhizae, Rhizoma & $\mathrm{V}^{*}$ \\
\hline Pinelliae, Rhizoma & I \\
\hline Piperis longi, Fructus & II \\
\hline Plantaginis, Herba & IV \\
\hline Plantaginis, Semen & IV \\
\hline Platycodonis, Radix & III \\
\hline Polygalae, Radix & $\mathrm{V}^{*}$ \\
\hline Polygoni avicularis, Herba & $\mathrm{V}^{*}$ \\
\hline Polygoni cuspidate, Rhizoma et Radix & $\mathrm{V}^{*}$ \\
\hline Polygoni multiflori, Radix & I \\
\hline Poria & II \\
\hline Prunellae, Spica & IV \\
\hline Psoraleae, Fructus & IV \\
\hline Puerariae, Radix & I \\
\hline Quinquefolii, Radix & II \\
\hline Rehmanniae, Radix & I \\
\hline Rhei, Radix et Rhizoma & II \\
\hline Rosae laevigatae, Fructus & $\mathrm{V}^{*}$ \\
\hline Salviae miltiorrhizae, Radix et Rhizoma & II \\
\hline Sanguisorbae, Radix & $\mathrm{V}^{*}$ \\
\hline Saposhnikoviae, Radix & III \\
\hline Sappan, Lignum & IV \\
\hline Sarcandrae, Herba & III \\
\hline Schisandrae, Fructus & I \\
\hline Schizonepetae, Spica & $\mathrm{V}^{*}$ \\
\hline Scrophulariae, Radix & I \\
\hline Scutellariae barbatae, Herba & $\mathrm{V}^{*}$ \\
\hline Scutellariae, Radix & II \\
\hline Sesami nigrum, Semen & IV \\
\hline Siegesbeckiae, Herba & II \\
\hline Sinapis albae, Semen & IV \\
\hline Sinomenii, Caulis & I \\
\hline Siraitiae (Momordicae), Fructus & III \\
\hline Solidaginis, Herba & $\mathrm{V}^{*}$ \\
\hline Sophorae flavescentis, Radix & II \\
\hline Sophorae immaturus, Flos & I \\
\hline Spatholobi, Caulis & III \\
\hline Stephaniae tetrandrae, Radix & I \\
\hline Trachelospermi, Caulis et Folium & $\mathrm{V}^{*}$ \\
\hline Tribuli, Fructus & II \\
\hline Trichosanthis, Fructus & IV \\
\hline Trichosanthis, Radix & IV \\
\hline Trigonellae, Semen & $\mathrm{V}^{*}$ \\
\hline Uncariae cum Uncis, Ramulus & I \\
\hline Vaccariae, Semen & IV \\
\hline Verbenae, Herba & $\mathrm{V}^{*}$ \\
\hline Violae, Herba & IV \\
\hline Viticis, Fructus & IV \\
\hline Xanthii, Fructus & IV \\
\hline Zanthoxyli, Pericarpium & I \\
\hline Zingiberis, Rhizoma & $\mathrm{V}^{*}$ \\
\hline Ziziphi spinosae, Semen & I \\
\hline
\end{tabular}


Table 2. Contents, alphabetically (Chinese names)

\begin{tabular}{|c|c|}
\hline Chinese name & Volume \\
\hline Aiye & IV \\
\hline Bai hua she she cao & III \\
\hline Bailian & $\mathrm{V}^{*}$ \\
\hline Baishao & I \\
\hline Baixianpi & $\mathrm{V}^{*}$ \\
\hline Baizhi & I \\
\hline Baizhu & I \\
\hline Bajitian & III \\
\hline Banlangen & II \\
\hline Banxia & I \\
\hline Banzhilian & $\mathrm{V}^{*}$ \\
\hline Beimu & I \\
\hline Beishashen & $\mathrm{V}^{*}$ \\
\hline Bianxu & $\mathrm{V}^{*}$ \\
\hline Bibo & II \\
\hline Buguzhi & IV \\
\hline Cang'erzi & IV \\
\hline Cangzhu & II \\
\hline Caodoukou & $\mathrm{V}^{*}$ \\
\hline Chaihu & I \\
\hline Cha-yeh & II \\
\hline Chenpi & II \\
\hline Cheqiancao & IV \\
\hline Cheqianzi & IV \\
\hline Chishao & I \\
\hline Chuanshanlong & II \\
\hline Chuanxinlian & I \\
\hline Chuanxiong & I \\
\hline Ciwujia & I \\
\hline Dafupi & $\mathrm{V}^{*}$ \\
\hline Dahuang & II \\
\hline Danggui & I \\
\hline Dangshen & I \\
\hline Danshen & II \\
\hline Difuzi & IV \\
\hline Digupi & II \\
\hline Dihuang & I \\
\hline Diyu & $\mathrm{V}^{*}$ \\
\hline Duhuo & I \\
\hline Duzhong & II \\
\hline Ezhu & II \\
\hline Fangfeng & III \\
\hline Fangji & I \\
\hline Fenbixie & II \\
\hline Fuling & II \\
\hline Fuzi & II \\
\hline Gancao & III \\
\hline Ganjiang & $\mathrm{V}^{*}$ \\
\hline Gegen & I \\
\hline Gouqizi & II \\
\hline Gouteng & I \\
\hline Gualou & IV \\
\hline Guangjinqiancao & III \\
\hline Guanhuangbo & II \\
\hline Gujincao & III \\
\hline Gusuibu & I \\
\hline Hehuanpi & IV \\
\hline Heizhima & IV \\
\hline
\end{tabular}

Chinese name $\quad$ Volume

Heshouwu

Honghua

Houpo

Huaihua

Huaimi

Huajiao

Huangbo

Huanglian

Huangqi

Huangqin

Huhuanglian

Huluba

Huzhang

Jianghuang

Jiaogulan

Jiegeng

Jiezi

Jili

Jingjiesui

Jinqiancao

Jinyingzi

Jinyinhua

Jiucaizi

Jixueteng

Juemingzi

Juhua

Kushen

Kuxingren

Lianqiao

Lingzhi

Luobumaya

Luohanguo

Luoshiteng

Mabiancao

Mahuang

Maidong

Manjingzi

Mianbixie

Mohanlian

Moyao

Mudanpi

Mugua

Muxiang

Muzei

Niubangzi

Niuxi

Nüzhenzi

Qianghuo

Qianhu

Qingfengteng

Qinghao

Qingpi

Qingxiangzi

Qinjiao

Qinpi

Rendongteng

Renshen

Rougui

Ruxiang

\begin{tabular}{|c|c|}
\hline Chinese name & Volume \\
\hline Sangbaipi & II \\
\hline Sangye & II \\
\hline Sangzhi & IV \\
\hline Sanqi & II \\
\hline Shanyao & II \\
\hline Shanyinhua & II \\
\hline Shanzhaye & III \\
\hline Shanzhaye & III \\
\hline Shanzhuyu & IV \\
\hline Sharen & I \\
\hline Shechuangzi & II \\
\hline Shegan & I \\
\hline Shengma & II \\
\hline Shenjincao & III \\
\hline Sichangpu & II \\
\hline Sigualuo & III \\
\hline Suanzaoren & I \\
\hline Sumu & IV \\
\hline Taoren & $\mathrm{V}^{*}$ \\
\hline Tianhuafen & IV \\
\hline Tianma & I \\
\hline Tusizi & $\mathrm{V}^{*}$ \\
\hline Wangbuliuxing & IV \\
\hline Weilingxian & I \\
\hline Wuweizi & I \\
\hline Wuyao & $\mathrm{V}^{*}$ \\
\hline Wuzhuyu & I \\
\hline Xiakucao & IV \\
\hline Xiangfu & III \\
\hline Xinyi & II \\
\hline Xixiancao & II \\
\hline Xixin & I \\
\hline Xiyangshen & II \\
\hline Xuanshen & I \\
\hline Xuduan & II \\
\hline Yanhusuo & II \\
\hline Yimucao & II \\
\hline Yinchen & II \\
\hline Yinxingye & $\mathrm{V}^{*}$ \\
\hline Yinyanghuo & II \\
\hline Yizhihuanghua & $\mathrm{V}^{*}$ \\
\hline Yuanzhi & $\mathrm{V}^{*}$ \\
\hline Yujin & II \\
\hline Yuxingxao & I \\
\hline Zangchangpu & II \\
\hline Zelan & I \\
\hline Zexie & II \\
\hline Zhicaowu & II \\
\hline Zhimu & I \\
\hline Zhiqiao & $\mathrm{V}^{*}$ \\
\hline Zhishi & $\mathrm{V}^{*}$ \\
\hline Zhizi & I \\
\hline Zhongjiefeng & III \\
\hline Zhuru & III \\
\hline Zicao & $\mathrm{V}^{*}$ \\
\hline Zihuadiding & IV \\
\hline
\end{tabular}


tetrandra (Hanfangji) was mistaken for the root of Aristolochia fangji (Guanfangji). The latter contains the carcinogenic aristolochic acid which can produce severe nephrotoxic side effects. A similar Chinese drug is the tetraploid Acorus tatarinowii with a high content of carcinogenic $\beta$-asarone in contrast to the diploid Acorus calamus L., known officially in most Western countries. This must also be corrected in one of the next Chinese Pharmacopoeias. Meanwhile, special chromatographic methods were developed and described in the analytical monographs to avoid such falsifications.

\section{Great Variability of Plant Species}

Several herbal drug monographs of the Chinese Pharmacopoeia list more than 2 species or subspecies, and sometimes up to 8 species labelled as synonyms, subspecies or subvarieties. It is assumed that all species contain the same constituents in the same amount. In 20 years of TLC and HPLC fingerprint investigations, we have shown that in many cases considerable differences were detectable between the single species and the main official drugs. Correspondingly, it may be suggested that a great number of the 'subspecies' do not possess the same pharmacological and therapeutic efficacy. This fact must be taken into consideration.

\section{Processing of TCM Drugs}

Apart from simply cutting and cleaning of the raw drugs, the Chinese Pharmacopoeia describes many other types of pretreatment or processing that is not considered in Western pharmacopoeias. In the Pharmacopoeia of the People's Republic of China, the processing is defined as 'a unique pharmaceutical technology that processes crude drugs according to their individual nature, and the requirements of drug dispensing, pharmaceutical preparation, and clinical use, following the Traditional Chinese Medicine theory'. However, in none of the monographs the necessity of spe- cific processing is substantiated. According to the Chinese Pharmacopoeia, processing can be achieved primarily through the following methods: roasting and broiling, scalding, calcining, carbonising, steaming, boiling, stewing with wine, vinegar or salt water and different kinds of stir baking. In one example, the alkaloidcontaining herbal drugs of Aconitum spp., Aconitum carmichaelii and Aconitum kusnezoffii, are treated with salt water, liquorice root, black beans and water after scalding by heating at high temperature with sand. The TLC and HPLC fingerprint analysis shows that in the processed roots, the alkaloids aconitine and mesaconitine are significantly degraded. Here, the necessity to reduce the aconitine content is clear because of its toxicity in higher doses (i.e. in an unprocessed form). Therefore, in Western countries such as Germany, aconitine preparations are acceptable only in homeopathic dilution form (e.g., as aconitum D6 or D12). This means that it is mandatory to limit the proportion of aconitine to a stipulated level.

As far as the processing methods of the Chinese Pharmacopoeia are concerned, they must be replaced by the modern phytochemical methods demanded by the German and by most European drug regulation authorities.

\section{Acknowledgement}

We are grateful to Mr. Anton Staudinger, TCM hospital Bad Kötzting, for financial support of the Chinese drug monographs.

\section{Disclosure Statement}

H.W. is chief of the drug control centre for TCM drugs, located at the University of Munich and member of the hospital's scientific advisory board. R.B. is member and D.M. is chair of this board.

\section{References}

1 Wagner H, Bauer R, Melchart D, Xiao P-G, Staudinger A (eds): Chromatographic Fingerprint Analysis of Herbal Medicines, vol. 1. Wien, Springer, 2011.

2 Wagner H, Bauer R, Melchart D, Xiao P-G, Staudinger A (eds): Chromatographic Fingerprint Analysis of Herbal Medicines, vol. 2. Wien, Springer, 2011.
3 Wagner H, Bauer R, Melchart D, Xiao P-G, Staudinger A (eds): Chromatographic Fingerprint Analysis of Herbal Medicines, vol. 3. Wien, Springer, 2015.
4 Chinese Pharmacopoeia Commission (ed): Pharmacopoeia of the People's Republic of China 2010, English Edition vol. I, Appendix IID A-25. Beijing, China Medical Science Press, 2010. 